\title{
Endotoxin Tolerance as a Key Mechanism for Immunosuppression
}

\author{
Subhra K. Biswas and Irina N. Shalova \\ Singapore Immunology Network, BMSI, A*STAR
}

Singapore

\section{Introduction}

Inflammation is a complex pathophysiological phenomenon orchestrated by immune cells in response to infection and/or tissue damage (Nathan, 2002; Foster \& Medzhitov, 2009). It serves protective mechanism against pathological insults and aims to re-instate homeostasis. Monocytes/macrophages are the first line of immune cells to detect and response to "danger signals" in an organism (e.g. pathogens, tissue damage). The detection of pathogens and/or endotoxins by these cells is mediated through pattern recognition receptors (PRRs) such as Toll-like receptors (TLRs) which triggers a robust and inflammatory reaction (Figure 1). However, uncontrolled inflammation can lead to extensive tissue damage and manifestation of pathological states like sepsis, autoimmune diseases, metabolic diseases and cancer (Foster \& Medzhitov, 2009). Thus, the innate immune cells 'adapt' themselves in the later phase of inflammation to tune down this response and promote resolution of inflammation leading to healing and tissue repair (Figure 1).

Organisms as well as their immune cells have developed mechanisms to protect themselves from excessive inflammation in response to endotoxins. Endotoxin tolerance (ET) is such an adaptation wherein organisms or their innate immune cells (like monocytes/macrophages) show diminished response to endotoxins as a result of prior exposure to low doses of endotoxins (Foster \& Medzhitov, 2009; Biswas et al., 2007; Dobrovolskaia \& Vogel, 2002; Fan \& Cook, 2004; Cavaillon \& Adib-Conquy, 2006). In other words, the organism or their immune cells have developed a "tolerance" to endotoxin. Clinically, this phenomenon can be observed in monocytes/macrophages in patients with sepsis, trauma, surgery or pancreatitis (Cavaillon et al., 2003; Monneret et al., 2008). In most of these cases ET contributes to immunosuppression, while in sepsis it has been linked to mortality as well (Figure 1) (Monneret et al., 2008). These and other facts have suggested ET as a key mechanism for immunosuppression associated with diverse pathological conditions. In this chapter, we will review the in vitro and in vivo evidences for ET, as well as an insight into the cellular and molecular basis of this phenomenon. In addition, the pathophysiological implications of ET will be also discussed.

\section{In vitro and in vivo evidences for ET}

ET has been observed both in vitro and in vivo in animal models as well as in humans (Biswas et al., 2007; Dobrovolskaia \& Vogel, 2002; Cavaillon \& Adib-Conquy, 2006; Biswas \& 


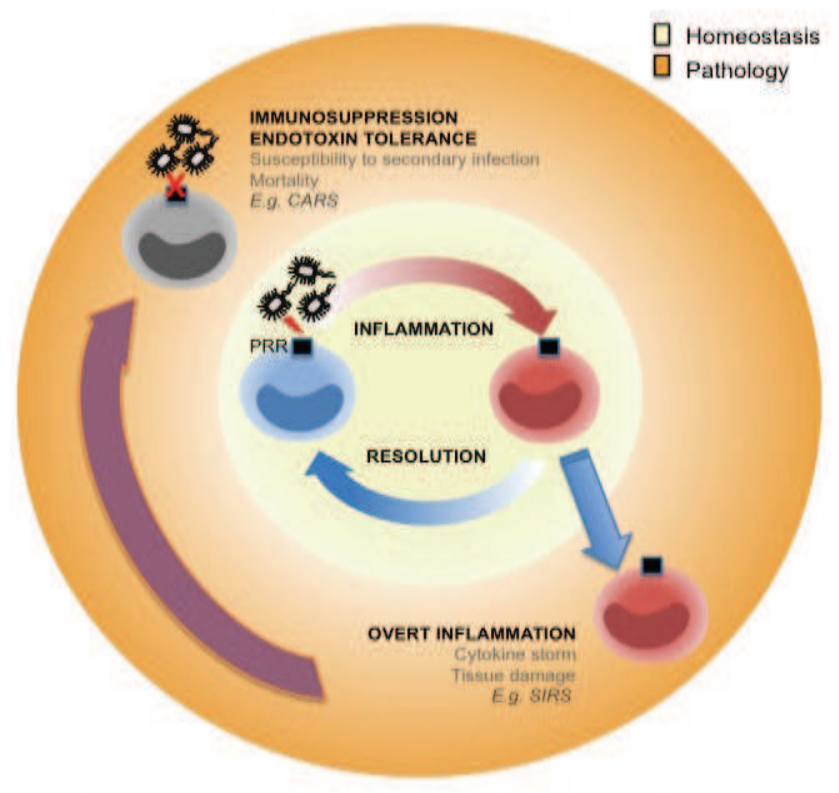

Fig. 1. Inflammation and resolution are pathophysiological responses in host defense and homeostasis. Inflammation is necessary to trigger a defense response against pathogens, while resolution promotes healing and re-instates homeostatic conditions.

Monocytes/macrophages detect and respond to pathogens via PRRs to mediate both inflammation and resolution. However, exaggerated inflammation can lead to deleterious effects like cytokine storm and tissue damage (e.g. in SIRS). As a protective response to this overt inflammation, an immunosuppressive or endotoxin tolerant phase (e.g. CARS) ensues, which in the case of sepsis leads to susceptibility to secondary infection and even mortality. SIRS: Systemic inflammatory response syndrome; CARS: Compensatory anti- inflammatory response syndrome

Tergaonkar, 2007; del Fresno et al., 2009; Foster et al., 2007; Dobrovolskaia et al., 2003; Medvedev et al., 2000). The first report of ET was by Paul Beeson in 1946. He observed that repeated injection of typhoid vaccine in rabbits caused a progressive reduction of fever induced by the vaccine (Foster \& Medzhitov, 2009). Similarly, in humans who were recovering from typhoid fever or malaria, wherein re-challenge with endotoxin showed reduced fever (Cavaillon \& Adib-Conquy, 2006). In mice, prior injection with a sublethal dose of Lipopolysaccharide (LPS) protected them from a subsequent and otherwise lethal dose of LPS (Cavaillon \& Adib-Conquy, 2006). This study also showed monocytes/macrophages as the principal cells responsible for the induction of ET in vivo. Subsequently, several in vitro studies have confirmed ET in murine macrophages as well as human monocytes when re-challenged in vitro with LPS, following a prior exposure to suboptimal levels of endotoxin (e.g. LPS). The key readout for ET in these cells was the drastic reduction of $\mathrm{TNF} \alpha$ production as compared to the cells exposed to endotoxin only once (Biswas et al., 2007; Dobrovolskaia \& Vogel, 2002; Cavaillon \& Adib-Conquy, 2006; del Fresno et al., 2009; Foster et al., 2007). Transcriptome studies have expanded our 
understanding of the gene expression response related to ET in murine macrophages (Dobrovolskaia \& Vogel, 2002; Dobrovolskaia et al., 2003; Medvedev et al., 2000) and human monocytes (Cavaillon \& Adib-Conquy, 2006; Chan et al., 2005; Chen et al., 2009; El Gazzar et al., 2009; Melo et al., 2010; Pena et al., 2011). These studies have not only shown the downregulation of a large panel of pro-inflammatory genes (the "tolerized" genes), but also defined a subset of "non-tolerant" whose transcription remained unaffected or even upregulated in the tolerized cells. For example, inflammatory cytokines/chemokines like TNF $\alpha$, IL-6, IL-12, IL-1 $\beta$, CCL3 and CCL4 were downregulated upon LPS re-stimulation of the endotoxin tolerized cells. In contrast, the upregulated genes were more varied, consisting of anti-inflammatory cytokines such as IL-10, TGF $\beta$ and IL-1RA; scavenging Ctype lectin receptors such as MARCO, CLEC4 $\alpha$, CD136, CD23, and CD64; negative regulators such as IRAK-M and a variety of anti-microbial genes (e.g. FPR1, AOAH and RNASET2) (del Fresno et al., 2009; Foster et al., 2007; Mages et al., 2007; Draisma et al., 2009; Pena et al., 2011). Several genes related to tissue remodeling and repair (e.g. VEGF, MMP, FGF2) were also upregulated. Transcriptomic analysis of murine macrophages from an in vivo LPS tolerance model confirmed some of the above findings as well as the downregulation of genes related to the cell death pathway (e.g. PARP-1, caspase 3, FASL and TRAIL) in LPS tolerant macrophages (Melo et al., 2010). These results have prompted the idea of ET as a case of gene re-programming rather than "tolerance" which suggests an overall downregulation of responses.

Functionally, endotoxin-tolerant monocytes are characterized by increased phagocytic ability but an impaired antigen presentation capacity (del Fresno et al., 2009; Monneret et al., 2004). Increased phagocytosis was suggested in this study to be due to the upregulated expression of the cell surface receptor CD64, whereas impaired antigen presentation was possibly due to downregulated expression of several MHC Class II molecules (e.g. HLADRs) and the master regulator of MHC Class II expression, CIITA (del Fresno et al., 2009; Monneret et al., 2004). IL-10 and TGF $\beta$ have been implicated in downregulate MHC Class II and the CD86 co-stimulatory molecule in endotoxin-tolerant human monocytes (Wolk et al., 2000; Wolk et al., 2003; Schroder et al., 2003). Increased production of tissue remodeling factors like VEGF, MMPs and FGF2 was related to the enhanced capacity of endotoxin tolerized monocytes in wound healing assays (Pena et al., 2011). Collectively, these studies observations may imply some functional relevance. For example, downregulation of inflammatory cytokines coupled with upregulation of anti-inflammatory cytokines as well as tissue remodeling factors may help to check against an overt inflammation and promote tissue repair, while increased phagocytic capability may be crucial to killing and clearance of bacteria. Additionally, downregulation of death-related genes would protect macrophages from death with possible implications on survival (Melo et al., 2010). However, further studies would be needed to demonstrate the occurrence of mechanism in vivo in animal models of sepsis progression.

In the line with the observations in monocytes/macrophages, ET affects dendritic cells (DC), neutrophils as well as some non-immune cells, like endothelial cells of the intestine (Ogawa et al., 2003). Endotoxin-tolerant DC show a downregulation of IL-12, TNF $\alpha$ and IL-6 expression, but enhanced IL-10 expression and endocytosis (Sharabi et al., 2008; Albrecht et al., 2008). Endotoxin-tolerant neutrophils demonstrate loss of TLR4 expression and impaired respiratory burst, but retain their proinflammatory cytokine phenotype (Parker et al., 2005). However, a full scale dissection of ET in different blood cell lineages and tissues would be particularly important to better understand the impact of this phenomenon at the organism level. 


\section{Polarization of myelomonocytic cells in ET}

A characteristic feature of monocytes and macrophages is their functional diversity and plasticity whereby these cells can display a variety of functional phenotypes depending on the microenvironment stimuli they encounter (Gordon \& Taylor, 2005; Biswas and Mantovani, 2010). Analogous to the Th1 and Th2 polarization scheme, two distinct activation states of macrophages have been defined, namely, classical or M1 activation and alternative or M2 activation state (Mantovani et al., 2004; Biswas \& Mantovani, 2010) (Figure 2).
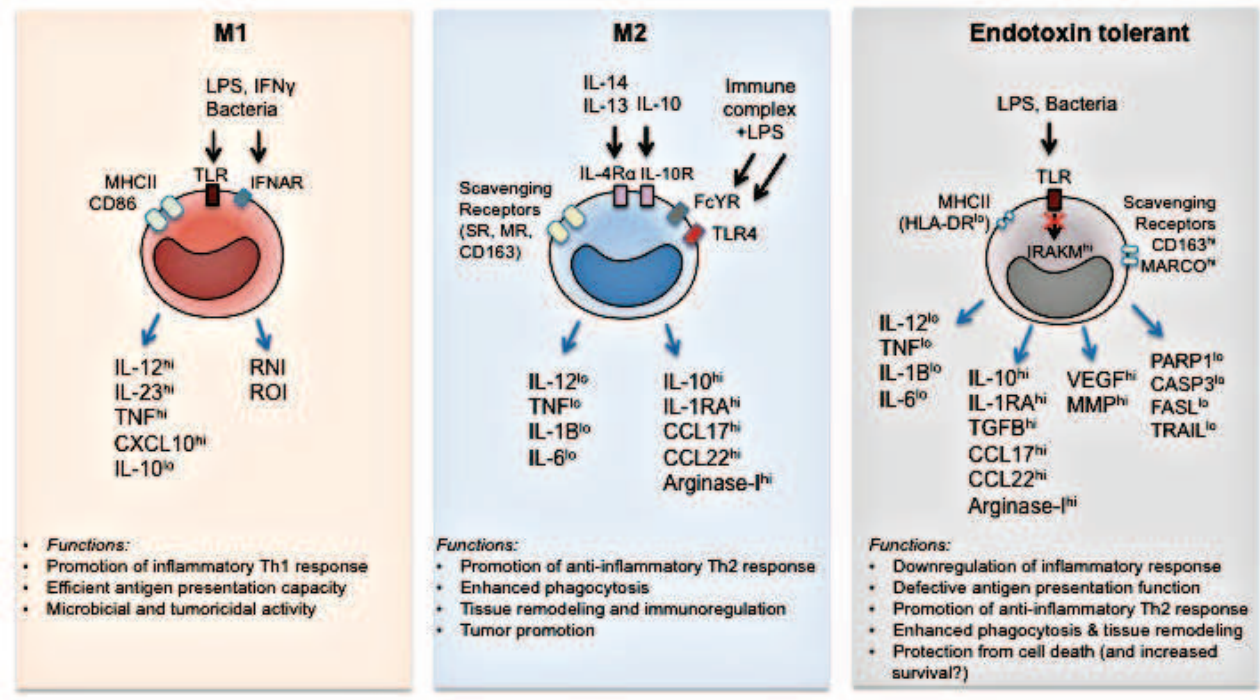

Fig. 2. Polarization states of monocytes and macrophages. Figure summaries the salient characteristics and functional properties defining the M1 and M2 polarization states. The figure also shows the salient properties of endotoxin tolerized monocytes and macrophages (as revealed by current studies) indicating them to be an M2 polarized population. SR: Scavenging receptor; MR: Mannose receptor

Th1 cytokines like IFN $\gamma$ as well as microbial stimuli (e.g. LPS) polarize macrophages to an M1 state whereas Th2 cytokines like IL-4, IL-13 or IL-10, glucocorticoids and immune complexes plus LPS, polarize macrophages to an M2 state. M1 macrophages show inflammatory characteristics with increased expression of proinflammatory cytokines like IL-12, TNF $\alpha$, IL23, CXCL10, reactive nitrogen and oxygen intermediates (RNI/ROI) but downregulate IL-10 expression. These cells display microbicidal and tumoricidal activity. In contrast, M2 macrophages produce very less inflammatory cytokines but upregulate the expression of antiinflammatory cytokines (e.g. IL-10), arginase I, as well as factors which promote tissue remodeling, angiogenesis, wound healing and tumor promotion. It may be emphasized that M1 and M2 phenotypes represent extremes of a spectrum of macrophage functional states (Mantovani et al., 2004; Mosser \& Edwards, 2008). The occurrence of mixed phenotype with overlapping M1 and M2 characteristics as well as plasticity between these two phenotypes have been observed in vivo (Biswas \& Mantovani, 2010). In fact, the plasticity of macrophages from an M1 to an M2-like state is integral to their role in inflammation and resolution. 
Several lines of evidences suggest endotoxin-tolerant monocytes/macrophages to resemble an M2 polarized population (Figure 2). These characteristics include downregulation of inflammatory cytokines (e.g. IL-12, TNF $\alpha$ ) and upregulation of anti-inflammatory cytokines (e.g. IL-10), scavenging receptor and efficient phagocytosis (del Fresno et al., 2009; Mantovani et al., 2005). Further, endotoxin tolerized mouse macrophages to express typical markers of M2 polarization like Arg1, CCL17 and CCL22 (Porta et al., 2009). Similarly, M2like Gr1+CD11b+ myeloid suppressor cells with increase IL-10 production and T-cell suppressive phenotype has also been reported in a murine polymicrobial sepsis model (Delano et al., 2007). More recent study on human monocytes confirmed its M2 polarization characterized by upregulation of scavenging receptors (MARCO, CD163, CD23), tissue remodeling genes (VEGF, FGF, MMPs) and M2-specific cytokine/chemokine genes (IL-10, CCL22 and CCL24) (Pena et al., 2011). The fact that endotoxin tolerized monocytes/macrophages are M2 polarized population is also in line with the observation of a Th2-polarized adaptive immune response in LPS-injected healthy donors and in murine polymicrobial sepsis (Delano et al., 2007; Lauw et al., 2000). However, the actual polarization state of monocytes and macrophages during endotoxin tolerance in vivo may be more complex, as with most pathological situations.

\section{Sepsis is a paradigm for ET}

Sepsis is a complex syndrome characterized by dysregulated inflammation and systemic bacterial infection. It consists from two phases. The first early phase is called Systemic inflammatory response syndrome or SIRS (Figure 1). It is characterized by leukocytes activation, rapid release of cytokines (also called 'Cytokine Storm') and tissue injury (AdibConquy \& Cavaillon, 2009). The second late phase of sepsis is called Compensatory antiinflammatory response syndrome or CARS (Figure 1). The CARS is characterized by leukocyte deactivation, immunosuppression and endothelial/epithelial dysfunction. This phase resembles an endotoxin-tolerant state (Monneret et al., 2008; Buras et al., 2005). In fact, some studies have linked this immunosuppressive or ET phase to mortality in sepsis patients (Monneret et al., 2008; Adib-Conquy \& Cavaillon, 2009; Hotchkiss et al., 2009; Pachot et al., 2006). In line with the above observation, sepsis blood monocytes show a phenotype similar to ET. This is characterized by i) a downregulation of proinflammatory cytokines like TNF $\alpha$, IL-6, IL-1 $\alpha$, IL-1 $\beta$ and IL-12 upon ex vivo LPS challenge as compared to that of monocytes from healthy donors (Monneret et al., 2008; Draisma et al., 2009; Munoz et al., 1991a,b); ii) downregulation of expression of MHC Class II molecules, CD86 and CIITA (Pachot et al., 2006; Manjuck et al., 2000); and iii) upregulation of anti-inflammatory cytokines like IL-10, TGF $\beta$ and IL-1RA (Draisma et al., 2009; Monneret et al., 2004; Cavaillon et al., 2005). Further, the decreased monocyte IL-12 production in trauma patients correlates to impaired T-cell proliferation and a polarization towards a Th2 response (Monneret et al., 2008; Hotchkiss \& Karl, 2003).

Paralleling the biphasic nature of sepsis progression from SIRS to CARS, monocytes are also believed to mirror a plasticity of their phenotype from an inflammatory to an antiinflammatory endotoxin tolerant. However, whether this is a cause or effect of the biphasic nature of sepsis and what are the triggers for this switch in the monocyte/macrophage phenotype remains to be investigated. It is believed that exposure to chronicle level of inflammatory substances as well as products of tissue damage at the early phase of sepsis may trigger mechanisms which stimulate endotoxin tolerance of monocytes in the later 
phase of sepsis. One of the examples of such dual regulation could be hyaluronic acid (HA), a component of the extracellular matrix. At the early phase of inflammation macrophages and neutrophils release hyaluronase that degrade HA. At the same time, HA inhibit TNF $\alpha$ expression and activate IL10 production in macrophages that help to block inflammation (Kuang et al., 2007). Moreover HA activates Matrix metalloprotease (MMP) which, in turn, activates the anti-inflammatory cytokine TGF $\beta$ (Nathan, 2002; Adair-Kirk \& Senior, 2008). Another interesting molecule is COX2, which is responsible for prostaglandin E2 (PGE2) production. Sepsis macrophages show high expression of COX2; however accumulation of PGE2 can inhibit COX2 expression in a negative feedback manner and stimulate the production of anti-inflammatory compounds like lipoxins (Serhan et al., 2007). Even the phagocytosis of apoptotic neutrophils, that take place at late phase of inflammation, can stimulate macrophages in anti-inflammatory mode that includes the production of TGF $\beta$ (Fadok et al., 1998). In contrast to the biphasic nature of sepsis discussed above, some authors have suggested host response to sepsis as concurrent process of overt inflammatory and immunosuppression. This seems plausible since sepsis monocytes show an inflammatory phenotype (as compared to normal monocytes), yet displaying an endotoxin phenotype upon further activation.

\section{Molecular mechanisms driving ET}

\subsection{Role of MyD88 and TRIF pathways}

Innate immune cells detect pathogen through pattern recognition receptors (PRR). While there exist a diverse array of secreted, transmembrane and cytosolic PRRs which respond to various danger signals (Iwasaki \& Medzhitov, 2010), we focus on Toll-like receptor 4 (TLR4), the major PRR involved in the detection of Gram-negative bacteria and their associated endotoxins (e.g. Lipopolysaccharide, LPS; Lipid A) (Beutler, 2004; O’Neill \& Bowie, 2007). TLR4 signaling is mediated by two distinct adaptors, namely, MyD88 and TRIF1 (Figure 3) (Kawai \& Akira, 2011).

The MyD88-dependent pathway leads to the activation of the transcription factor NF- $\mathrm{KB}$ and inflammatory genes like TNFA, IL1B, IL6 and IL12A (Figure 3). The TRIF-dependent pathway upregulates the transcription factor IRF3 which induces expression of IFN $\beta$ and this, in turn, activates transcription factor STAT1 and expression of interferon-inducible genes like CCL5 and CXCL10 (Figure 3) (Kawai \& Akira, 2011; Yamamoto et al., 2003; Biswas \& Lopez-Collazo, 2009). However, crosstalk exists between both these pathways.

Several studies have indicated defects in the TLR4 pathways as a mechanistic basis of ET in monocytes and macrophages. These defects can be at multiple levels starting from the receptor, adaptors, signaling molecules, and transcription factors (Biswas \& Lopez-Collazo, 2009). For example, downregulation of TLR4, decrease in TLR4-MyD88 complex formation,

\footnotetext{
${ }^{1}$ Abbreviation for signaling molecules: AP1: activator protein 1; ATF3: Activating transcription factor 3; BCL3: B-cell CLL/lymphoma 3; FLN29: TRAF-type zinc finger domain containing 1(TRAFD1); GAS6: Growth arrest-specific 6; HA: Hyaluronic acid; IRAK-M: interleukin-1 receptor-associated kinase 3; IRF3: Interferon regulatory factor 3; JNK: Jun N-terminal kinase; LPS: Lipopolysaccharide; MKP1: MAP kinase phosphatase 1; MyD88: Myeloid differentiation 88; NF-kB: Nuclear factor-kappa B; SIGIRR: Single immunoglobulin IL-IR-related; SOCS: Suppressor of cytokine signaling; ST2: Suppression of tumorigenicity 2; STAT: Signal transducer and activator of transcription; TBK1: TANKbinding kinase 1; TRAF3: TNF receptor-associated factor 3; TRIF: TIR domain-containing adapter protein inducing IFN-beta.
} 


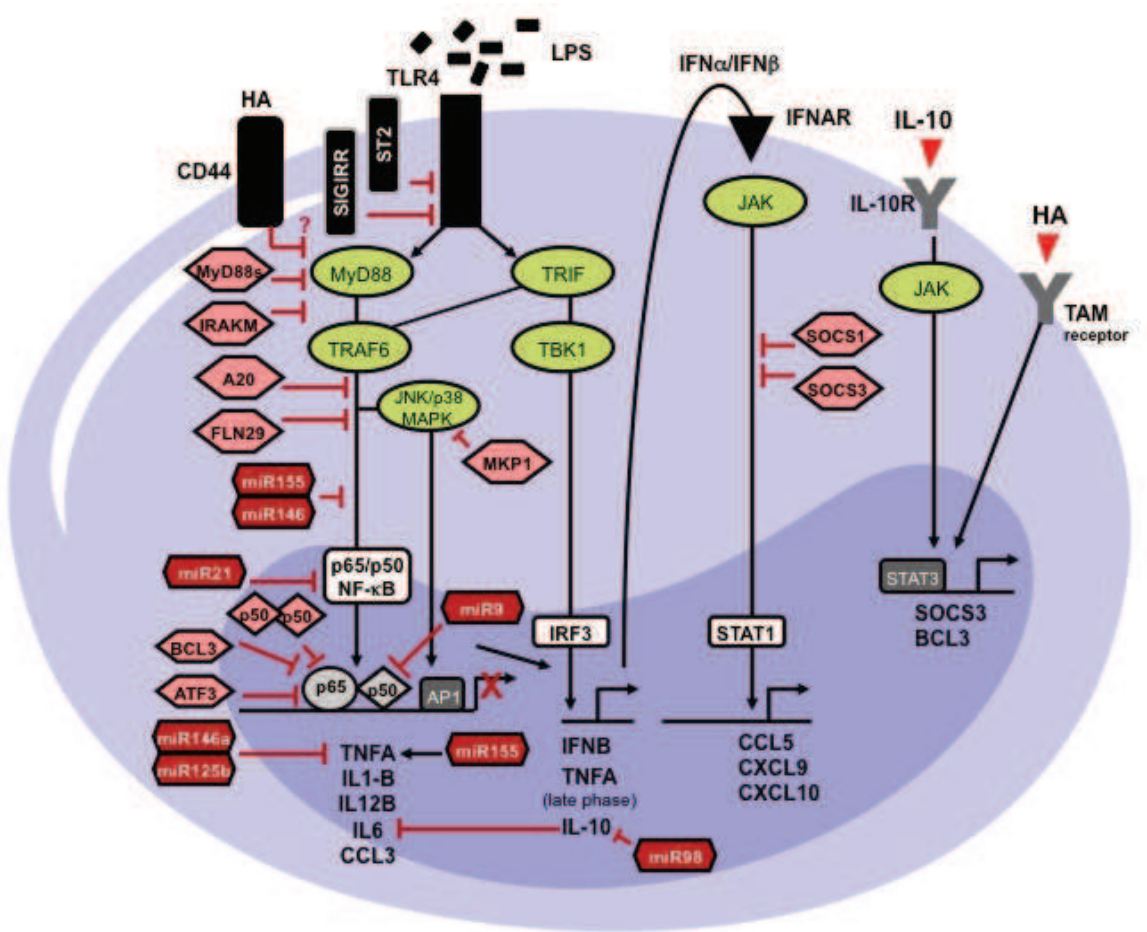

Fig. 3. Toll-like receptor 4 (TLR4) pathway and its negative regulators implicated in endotoxin tolerance. TLR4 signaling is mediated by two distinct adaptor proteins, namely, MyD88 and TRIF. Signaling via MyD88 leads to phosphorylation-mediated degradation of $\mathrm{I} \kappa \mathrm{B} \alpha$, nuclear translocation of $\mathrm{p} 65 / \mathrm{p} 50 \mathrm{NF}-\mathrm{kB}$ and transcription of proinflammatory genes like TNFA, IL1B, IL12B, IL6, and CCL3. The MyD88 pathway activates MAPKs (e.g JNK, p38) and their downstream transcription factor, AP-1 which also regulates proinflammatory cytokine gene transcription. Signaling though TRIF pathway induces a phosphorylation cascade involving activation of TBK1 and the downstream transcription factor IRF3 leading to the expression of IFNB. Late-phase TNFA is transcribed through this pathway (Covert et al., 2005). IL-10 is induced through the TRIF pathway via TRAF3 or Type I Interferon (Chang et al., 2007; Hacker et al., 2006). Signaling though IL-10R and TAM receptors activates STAT3 which transcribes SOCS3 and BCL3. Both these molecules negatively regulate STAT1 and NF- $\mathrm{kB}$. Several negative regulators of the TLR4/IL-1R/NF-kB pathway (shown by pink boxes) as well as MicroRNAs (shown by red boxes) with relevance in ET are indicated on the figure. Hyaluronic acid (HA) signals though CD44 and is reported to downregulate TLR4 signaling and expression of proinflammatory genes (del Fresno et al., 2005; Kuang et al., 2007; Kuang et al., 2007). It may be noted that not all negative regulators shown on the figure have been validated in human. " $\perp$ " denotes inhibition; " $\rightarrow$ " denotes stimulation; "?" -denotes pathways not fully characterized

inhibition of IRAK-1 activity, as well as mitogen-activated protein kinases (MAPKs) and NF$\mathrm{kB}$ have been noted in endotoxin tolerized monocytes/macrophages (Fan \& Cook, 2004; Biswas \& Tergaonkar, 2007). While a majority of the above events are linked to defects in the 
MyD88-dependent pathway, several evidences point towards a non-redundant role for TRIF pathway in ET. The majority of the LPS-induced transcriptome in macrophages is TRIFdependent with several proinflammatory genes being controlled through this pathway (Bjorkbacka et al., 2004). In particular, TRIF pathway has been suggested to mediate the sustained, late-phase expression of $\mathrm{TNF} \alpha$, a cytokine known to induce ET upon chronic exposure (Covert et al., 2005; Beutler, 2004). Thus, it is possible that through the sustained expression of such proinflammatory factors the TRIF pathway may contribute to the induction of ET. In agreement, we have shown TRIF pathway to contribute to ET in mouse embryonal fibroblasts (Biswas et al., 2007). Further, the TRIF/IFN $\beta$ pathway is also been implicated to mediate expression of IL-10, which is upregulated in endotoxin tolerant macrophages and monocytes (Chang et al., 2007; Hacker et al., 2006). In contrast, in human monocytes, inhibition of TRIF-dependent signaling has been shown under endotoxin tolerance. Collectively, these evidences highlight the involvement of both MyD88- and TRIFdependent pathway in ET, although the relative contribution of each of these pathways in driving ET remains to be addressed.

\subsection{Differential NF-kB activity}

The transcription factor NF- $\kappa B$ is a key regulator of many inflammatory genes like TNF $\alpha$, IL-1 $\beta$, IL-6 and COX2. However, a switch in NF-אB function from an inflammatory to an anti-inflammatory has been noted in course of inflammation, which could be relevant to the mechanism of ET (Lawrence et al., 2001; Cavaillon \& Adib-Conquy, 2006). NF-kB functions as hetero- or homodimers with the Rel family transacting proteins p65, p50, c-rel, relB and p52 (Hayden \& Ghosh, 2008). During canonical NF-kB signaling, phosphorylation-induced proteosomal degradation of the inhibitor protein, I $\mathrm{B} B \alpha$, releases the $\mathrm{p} 65 / \mathrm{p} 50 \mathrm{NF}-\kappa \mathrm{B}$ heterodimer to translocate to the nucleus. There, it binds to the target gene promoter and induces gene transcription (Figure3). In contrast, the p50/p50 NF- $\mathrm{\kappa B}$ homodimers have an inhibitory effect wherein they compete with p65/p50 NF- $\mathrm{\kappa B}$ heterodimers and prevent their binding to inflammatory gene promoter, thereby inhibiting the transcription of these genes (Hayden \& Ghosh, 2008). In agreement, endotoxin-tolerant murine macrophages and human monocytes as well as monocytes from sepsis and trauma patients characterize by decreased NF- $\kappa B$ activity due to over-expression of p50 NF- $\kappa B$ homodimers and decreased level of the active p65-p50 NF- $\mathrm{BB}$ heterodimers (Cavaillon \& Adib-Conquy, 2006; ZieglerHeitbrock, 2001; Adib-Conquy et al., 2000). The impact of p50/p50 homodimers in the induction of ET is further justified by results from p50 -/- murine macrophages which cannot be rendered endotoxin tolerant upon prolonged treatment with LPS (Bohuslav et al., 1998; Wysocka et al., 2001). p50/p50 NF- $\mathrm{kB}$ homodimers besides inhibiting the expression of inflammatory genes like IL12p40, TNFA, NOS2 can also induce the expression of antiinflammatory genes like TGF $\beta$ and IL-10 which are also known to be upregulated in ET (Lawrence et al., 2001). Thus, the switching of NF-kB from p65/p50 to a p50/p50 dimer may be a possible mechanism for converting inflammatory monocytes/macrophages to an endotoxin tolerant state. In addition, other members of the NF- $\kappa B$ family such as $\mathrm{IkB} \alpha, \mathrm{IkB} \varepsilon$ and RelB have also been proposed in ET. Indeed, high level of inhibitory proteins $\mathrm{IkB} \alpha$ and $\mathrm{IkB} \varepsilon$ was reported in ET mouse macrophages, at the same time ET human monocytes were characterized by overexpression of RelB (Dobrovolskaia et al., 2003; Chen et al., 2009). However, the interplay of different NF-кB-ІкB family members in sepsis-induced immunosuppression and ET warrants further investigation. 


\subsection{Negative regulators of TLR4 pathway}

Many of the defects in the TLR4 pathway during ET have been attributed to the overexpression of negative regulators of this pathway. Endotoxin tolerant cells show high expression of negative regulators of TLR4 pathway, such as IRAK-M, MKP1, FLN29, ST2, SOCS1, short version of MyD88 (MyD88sh) (Liew et al., 2005; Lopez-Collazo et al., 2006; Escoll et al., 2003; Kobayashi et al., 2002) and SHIP (Rauh et al., 2005) (Figure 3). IRAK-M is the only molecule that is consistently overexpressed in human monocytes and mouse macrophages during ET as well as in low-grade endotoxemia in humans (del Fresno et al., 2009; van 't Veer et al., 2007; Kobayashi et al., 2002). For all others negative regulators the mechanism differs in human and mice. For example, ST2, SOCS1, and SHIP were not upregulated in human endotoxemia while their knockout mice failed to develop ET (del Fresno et al., 2009; van 't Veer et al., 2007; Liew et al., 2005; Rauh et al., 2005). Other negative regulators like A20 and MKP1 have not been considered as candidates in human ET, due to their very early induction during endotoxemia (van't Veer et al., 2007).

The list of putative negative regulators with relevance to ET is expanding. TREM-1 has been shown to play an important role in the developing of ET in leukocytes from Cystic Fibrosis patients (del Fresno et al., 2008). In particular, the soluble form of TREM-1 which plays an anti-inflammatory role may be the likely candidate (Gibot et al., 2004). TAM receptors (viz. Axl, Tyro3, Mer) are induced by Type I interferons downstream of TLR pathways and act as a negative feedback loop for TLR signaling through the induction of SOCS1 and SOCS3 (Rothlin et al., 2007). Thus, TAM receptors qualify as possible candidates that may contribute to ET. In accordance, TAM receptors have been implicated in the induction of immunosuppression in sepsis patients (Rothlin et al., 2007). Another new molecule called Twist-2 may also be implicated in ET via its regulatory role on IL-10 expression, which is upregulated in most endotoxin tolerant cells (Sharabi et al., 2008). Similarly, ATF3 is reported to downregulate IL-6 production and protect from LPS shock in mice, but its role in ET is still unknown (Figure 3) (Gilchrist et al., 2006).

\section{Chromatin modification and gene reprogramming in ET}

Transcriptomic analysis of human monocytes as well as mouse macrophages under ET state has shown profound gene reprogramming. Foster et al. demonstrated that epigenetic regulation was responsible for this gene reprogramming during ET (Foster et al., 2007). Histone modifications can lead to changes in the degree of coiling of the DNA which affects their accessibility to transcription. This constitutes an important epigenetic regulatory mechanism. Accordingly, deacetylation or methylation of histones promotes gene silencing, while acetylation or demethylation of histones stimulates transcription of target genes (Wilson, 2008). In the study by Foster et al., two sets of genes were identified: i) genes which were inhibited (i.e. Tolerant genes; e.g. inflammatory genes) and ii) genes which remained inducible or upregulated (i.e. Non-tolerant; e.g. antimicrobial genes) upon the second LPS challenge. LPS provoke histone methylation of Tolerant as well as Non-tolerant gene promoters (Foster et al., 2007). However, upon a second challenge with LPS, re-acetylation of histones was only observed for the promoter of Non-tolerant genes which led to RNA polymerase recruitment and their transcription. In contrast, no such event was observed for Tolerant gene promoters which remained inactive (Beutler, 2004). The upregulation of Nontolerant genes during the second LPS challenge was explained by histone modifications of their promoters during the initial LPS activation which primed them for subsequent transcription. Other evidences for histone modification causing the suppression of 
inflammatory genes during ET are also available. For example, binding of high-mobility group box 1 proteins (HMGB1) and histone H1 linker at the promoters of TNF $\alpha$ and IL-1 $\beta$ genes induces chromatin remodeling and gene silencing during ET (El Gazzar et al., 2009). Similarly, RelB directed histone H3K9 demethylation caused impaired p65 NF-KB transactivation at the IL1B promoter and silencing of the gene in endotoxin-tolerant human monocytic cell lines (Chan et al., 2005). It may be envisaged that chromatin remodeling in ET may depend on de novo synthesis of one or more factors during the initial LPS exposure (Foster et al., 2007). Supporting this idea, many LPS-induced primary gene products such as Brg1 and IkB $\zeta$ can modulate chromatin remodeling at the promoters of secondary response genes, thereby allowing their subsequent re-programming (Kayama et al., 2008; Ramirez-Carrozzi et al., 2006). In this context, the LPS-induced histone demethylase, JMJD3 has been shown to cause chromatin remodeling and transcription of M2 macrophage specific genes, suggesting a potential mechanism of how inflammatory macrophages may switch to an M2 phenotype during endotoxin tolerance (De Santa et al., 2007; Satoh et al., 2010). Collectively, the facts discussed here point towards an important role for epigenetic regulation in shaping the gene expression response in ET. However, the epigenetic landscape and the upstream signaling molecules that regulate this process remain to be characterized.

\section{MicroRNA-mediated regulation of ET}

MicroRNA is another important post-transcriptional regulatory mechanism for gene expression in many cellular processes including immune response (Bartel, 2009; Baltimore, 2008). Proinflammatory stimuli such as LPS, TNF $\alpha$, and IL-1 $\beta$ as well as ligands for TLR2 and TLR5 induce the expression of specific microRNAs that modulate TLR4 and IL-1 receptor (IL-1R) signaling pathways in monocytes/macrophages (Baltimore, 2008; O'Connell et al., 2007; Taganov et al., 2006). As reviewed recently, several microRNAs play a crucial role in the ET mechanism (Biswas \& Lopez-Collazo, 2009; Nahid et al., 2011). miR146 and miR155 were the first identified microRNAs, that could be stimulated by LPS in human monocytic cells (O'Connell et al., 2007; Taganov et al., 2006). miR146 was shown to inhibit TLR4/IL-1R signaling through post-transcriptional regulation of the signaling proteins, IRAK-1 and TRAF6 (Figure 3) (Baltimore et al., 2008; Taganov et al., 2006). Indeed, decrease of IRAK-1 protein but not its mRNA was observed during ET (Baltimore et al., 2008). Further, miR146a also was shown to inhibit TNF $\alpha$ at transcription as well as translation level during TLR4-induced gene reprogramming (Figure 3) (El Gazzar et al., 2011).

miR155 is another microRNA induced by LPS and double-stranded RNA through an autocrine and/or paracrine induction of TNF $\alpha$ (O'Connell et al., 2007). miR155 inhibits TLR4 signaling by targeting IKKE and promotes TNF $\alpha$ at the translational level (Figure 3) (Tili et al., 2007). In fact, mir155 knock-in mice are highly susceptible to LPS shock as a result of high levels of TNF $\alpha$ (Costinean et al., 2006). Contrary to this, miR125b is another LPSinducible microRNA that promotes TNF $\alpha$ degradation during LPS stimulation (Figure 3) (Tili et al., 2007). miR9 is also induced by LPS in monocytes and targets NF-kB1 (p105/p50NF- $\mathrm{kB}$ ) transcript thereby serving as a possible negative feedback mechanism on the inflammation (Bazzoni et al., 2009). A more recent study found miR98 to be involved in post-transcriptional control of IL-10 production during ET in macrophages (Liu et al., 2011). miR21 has been suggested to enhance IL-10 and inhibit NF- $\kappa B$ via regulation of the proinflammatory protein PDCD4 in LPS-treated human peripheral blood monocytes and hence be a possible candidate in mediating ET (Figure 3) (Sheedy et al., 2010). The growing 
list of microRNAs clearly shows them to act at multiple levels of the inflammatory pathway. However, the actual role of microRNAs in the control of ET could be at the late phase of inflammation wherein microRNAs act as a negative feedback loop inhibiting the TLR4 pathway and inflammatory cytokines at a post-transcriptional and translation level and thus promoting ET (El Gazzar \& McCall, 2010; Biswas \& Collazo, 2009).

\section{Contribution of immune cell apoptosis to ET}

Apoptosis of immune cells has been suggested to contribute to immunosuppression and ET in sepsis. Apoptosis of several types of cells like CD4+ T-cells, B-cells and follicular DCs was reported in the spleen for sepsis patients (Hotchkiss \& Karl, 2003). Interestingly, CD8+ T cells, NK cells, monocytes or macrophages showed no apoptosis during ET. Recent studies have shown that differential modulation of the gene expression of cell death pathway during in vivo LPS tolerance helps to protect macrophages from apoptosis and results in enhanced survival of mice (Melo et al., 2010). In line with this, LPS-tolerant macrophages were found to have reduced apoptosis compared to naive macrophages, during polymicrobial sepsis. Depletion of DCs has been noted in human and mice sepsis (Hotchkiss et al., 2002; Efron et al., 2004), whereas, increased DC survival in mice stimulates resistance to endotoxin shock and attenuate LPS-induced immunosuppression (Gautier et al., 2008). Although, the role of apoptosis in ET still warrants investigation, the evidence at hand emphasize the importance of immune cell apoptosis in mediating sepsis-induced immunosuppression.

\section{ET as an 'adaptive' response of innate immunity}

One of the defining paradigms of the adaptive immunity is the ability to mount an enhanced and tailored immune response upon secondary exposure to the same antigen. Similarly, sensing of microbial components by macrophages not only results in their functional activation, but also in reshaping subsequent responses to microbes. Thus, innate immunity also has a built-in 'adaptive' component (Bowdish et al., 2007; Mantovani, 2008). Supporting this concept, studies with in germ-free mice indicated their inability to trigger an inflammatory response following endotoxin challenge (Souza et al., 2004). Further studies revealed that innate immune sensing by commensal bacteria was essential for mounting an acute inflammatory response to subsequent endotoxin stimulation (Amaral et al., 2008). Similarly, bacterial components can induce an upregulation of the scavenging receptor MARCO in macrophages which in turn influences their phagocytic and cytokine secreting ability, poising them for an enhanced immune response to subsequent pathogenic challenge (Bowdish et al., 2007; Willment et al., 2003). ET presents an analogous situation where exposure to endotoxins influences subsequent responses to endotoxins by dampening inflammatory response. While we have restricted our discussion to ET mediated through TLR4 receptor by LPS or Gram-negative sepsis, stimulation by other TLR ligands and Grampositive sepsis can also lead to ET. This phenomenon is referred to heterotolerance or crosstolerance (Dobrovolskaia et al., 2003). Pretreatment of macrophages with TLR2 ligands like lipoteichoic acid (LTA), Pam3Cysk4 or MALP2 stimulates ET to LPS in these cells (Dobrovolskaia et al., 2003; Sato et al., 2000). Damage-associated molecular patterns (DAMPs), such as HA, HMGB1, fibronectin, NOD2, also stimulate ET under certain conditions (Kuang et al., 2007; Liu et al., 2008; Adair-Kirk \& Senior, 2008; Kwon et al., 2004; Kim et al., 2008). Interestingly, the fact that macrophages can 'remember' a prior exposure to 
endotoxin (as seen in ET) is reminiscent of an 'immunological memory', another feature of the adaptive immune system. Based on the above observations, it may be suggested that ET represents an 'adaptive' response of innate immunity and a part of the so-called 'trained immunity' (Biswas \& Mantovani, 2010; Netea et al., 2011).

\section{ET as a common paradigm for immunosuppression in many diseases}

One of the key characteristics defining ET is a downregulation of the inflammatory response of innate immune cells like monocytes/macrophages subsequently challenged with endotoxin. Such endotoxin refractory state has been observed in the innate immune cells associated with various pathologies like hepatic and renal ischemia, coronary occlusion, acute coronary syndromes, cystic fibrosis and even cancer (del Fresno et al., 2009; Nimah et al., 2005; Ziegler-Heitbrock, 2001; Wilson, 2008).

Similar to ET associated with sepsis, the incidence of such refractory states in acute pulmonary syndromes and cystic fibrosis induces susceptibility to nosocomial infections and complications. Further, mechanistic paradigms common to ET (and sepsis) have also been observed in other diseases. For example, IRAK-M, a major mediator of ET in monocytes/macrophages (Biswas \& Lopez-Collazo, 2009), is upregulated in circulating monocytes of patients with gram-negative sepsis, acute coronary syndrome and cystic fibrosis, together with poor TNF $\alpha$ induction to LPS challenge (Palsson-McDermott et al., 2009; Ziegler-Heitbrock, 2001; del Fresno et al., 2009). In addition to their refractoriness to endotoxins, cystic fibrosis monocytes also show impaired antigen presentation but potent phagocytic activity similar to the endotoxin tolerant human monocytes (del Fresno et al., 2009). In cancer the induction of tumor-induced immunosuppression is widely known phenomenon. In line with this, tumor associated macrophages (TAMs) show an immunosuppressive phenotype similar to ET. TAMs are refractory to ex vivo LPS challenge and show decreased production of inflammatory cytokines like IL-12p40 and TNF $\alpha$, but upregulation of anti-inflammatory cytokines, IL-10 and TGF $\beta$, similar to ET macrophages

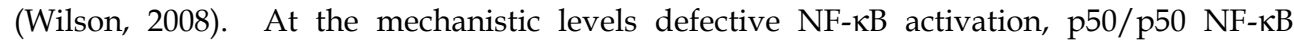
homodimers overexpression and a functional TRIF pathway have been observed in these cells, similar to ET (Biswas et al., 2007; Wilson, 2008; Kayama et al., 2008). Co-culturing human monocytes with cancer cells causes refractoriness to endotoxin which is suggested to be linked to the upregulation of IRAKM, as known for ET (del Fresno et al., 2005). These observations show tumor-induced immunosuppression and ET to share many common characteristics. It may be possible that analogous to the chronic inflammation induced by exposure to low doses of endotoxin, smouldered inflammation associated with cancer may also induce a "tolerance" in the associated immune cells, thus giving rise to the immunosuppressive phenotype (Mantovani \& Sica, 2010). Taken together, the above observations strongly suggest the endotoxin tolerant state as a general paradigm for immunosuppression across different diseases. Importantly, this finding potentially enables to apply the lessons learnt from ET to provide clues in explaining immunosuppression associated with other pathologies.

\section{Conclusion}

Based on the evidences discussed in this review, it is clear that ET represents an 'adaptive' response of the innate immune system that protects against exaggerated inflammation. 
Accordingly, ET involves extensive gene reprogramming that supports the functional polarization of monocytes and macrophages, tuning down inflammatory response, but promoting phagocytosis, tissue repair and immunoregulatory functions. Besides being a protective response, ET is also associated with a variety of pathological conditions where it serves as a mechanism for immunosuppression. Such conditions often contribute to immune evasion, increased susceptibility to secondary infection and even mortality. Thus, a cellular and molecular understanding of ET will serve as a key step towards understanding of immunosuppression and its targeting in many diseases.

\section{Acknowledgment}

SKB and INS are supported by funding from Biomedical Research Council (BMRC), A*STAR, Singapore. The authors sincerely apologize to all those authors whose original works could not be quoted in this review due to space constraints.

\section{Reference}

Adair-Kirk, T.L. \& Senior, R.M. (2008) Fragments of extracellular matrix as mediators of inflammation. Int. J. Biochem. Cell Biol., 40, 6-7, 1101-1110.

Adib-Conquy, M. \& Cavaillon, J.M. (2009) Compensatory anti-inflammatory response syndrome. Thromb. Haemost., 101, 1, (January 2009), 36-47.

Adib-Conquy, M., Adrie, C., Moine, P., Asehnoune, K., Fitting, C., Pinsky, M.R., Dhainaut, J.F., \& Cavaillon, J.M. (2000) NF-kappaB expression in mononuclear cells of patients with sepsis resembles that observed in lipopolysaccharide tolerance. Am. J. Resp. Crit. Care Med., 162, 5, (November 2000), 1877-1883.

Albrecht, V., Hofer, T.P., Foxwell, B., Frankenberger, M., \& Ziegler-Heitbrock, L. (2008) Tolerance induced via TLR2 and TLR4 in human dendritic cells: role of IRAK-1. BMC Immunol., 9, (November 2008), 69.

Amaral, F.A., Sachs, D., Costa, V.V., Fagundes, C.T., Cisalpino, D., Cunha, T.M., Ferreira, S.H., Cunha, F.Q., Silva, T.A., Nicoli, J.R., Vieira, L.Q., Souza, D.G., \& Teixeira, M.M. (2008) Commensal microbiota is fundamental for the development of inflammatory pain. Proc Natl Acad Sci U S A., 105, 6, (February 2008), 2193 - 2197.

Baltimore, D., Boldin, M.P., O'Connell, R.M., Rao, D.S., \& Taganov, K.D. (2008) MicroRNAs: new regulators of immune cell development and function. Nat Immunol., 9, 8, (August 2008), 839-845.

Bartel, D.P. (2009) MicroRNAs: target recognition and regulatory functions. Cell, 136, 2, (January 2009), 215-233.

Bazzoni, F., Rossato, M., Fabbri, M., Gaudiosi, D., Mirolo, M., Mori, L., Tamassia, N., Mantovani, A., Cassatella, M.A., \& Locati, M. (2009) Induction and regulatory function of miR-9 in human monocytes and neutrophils exposed to proinflammatory signals. Proc Natl Acad Sci U S A, 106, 13, (March 2009), 5282-5287.

Beutler, B. (2004) SHIP, TGF-beta, and endotoxin tolerance. Immunity, 21, 2, (August 2004), 134-135.

Biswas, S.K. \& Mantovani, A. (2010) Macrophage plasticity and interaction with lymphocyte subsets: cancer as a paradigm. Nat Immunol. 11, 10, 889-896. 
Biswas, S.K. \& Tergaonkar, V. (2007) Myeloid differentiation factor 88-independent toll-like receptor pathway: sustaining inflammation or promoting tolerance. International Journal of Biochemistry and Cell Biology, 39, 9, 1582-1592.

Biswas, S.K. \& Lopez-Collazo, E. (2009) Endotoxin tolerance: new mechanisms, molecules and clinical significance. Trends Immunol., 30, 10, (October 2009), 475-487.

Biswas, S.K., Bist, P., Dhillon, M.K., Kajiji, T., Del Fresno, C., Yamamoto, M., Lopez-Collazo, E., Akira, S., \& Tergaonkar, V. (2007) Role for MyD88-independent, TRIF pathway in lipid A/TLR4-induced endotoxin tolerance. J Immunol., 179, 6, (September 2007), 4083-4092.

Björkbacka, H., Fitzgerald, K.A., Huet, F., Li, X., Gregory, J.A., Lee, M.A., Ordija, C.M., Dowley, N.E., Golenbock, D.T., \& Freeman, M.W. (2004) The induction of macrophage gene expression by LPS predominantly utilizes Myd88-independent signaling cascades. Physiol Genomics, 19, 3, (November 2004), 319-330.

Bohuslav, J., Kravchenko, V.V., Parry, G.C., Erlich, J.H., Gerondakis, S., Mackman, N., \& Ulevitch, R.J. (1998) Regulation of an essential innate immune response by the p50 subunit of NF-kappaB. J. Clin. Invest., 102, 9, (November 1998), 1645-1652.

Bowdish, D.M., Loffredo, M.S., Mukhopadhyay, S., Mantovani, A. \& Gordon, S. (2007) Macrophage receptors implicated in the 'adaptive' form of innate immunity. Microbes Infect., 9, 14-15, (November-December 2007), 1680-1687.

Buras, J.A., Holzmann, B., \& Sitkovsky, M. (2005) Animal models of sepsis: setting the stage. Nat Rev Drug Discov., 4, 10, (October 2005), 854-865.

Cavaillon, J.M. \& Adib-Conquy, M. (2006) Bench-to-bedside review: endotoxin tolerance as a model of leukocyte reprogramming in sepsis. Critical care (London, England), 10, 5, 233.

Cavaillon, J.M., Adrie, C., Fitting, C., \& Adib-Conquy, M. (2003) Endotoxin tolerance: is there a clinical relevance? J. Endotoxin Res., 9, 2, 101-107.

Cavaillon, J.M., Adrie, C., Fitting, C., \& Adib-Conquy, M. (2005) Reprogramming of circulatory cells in sepsis and SIRS. J Endotoxin Res., 11, 5, 311-320.

Chan, C., Li, L., McCall, C.E., \& Yoza, B.K. (2005) Endotoxin tolerance disrupts chromatin remodeling and NF-kappaB transactivation at the IL-1beta promoter. J. Immunol., 175, 1, (July 2005), 461-468.

Chang, E.Y., Guo, B., Doyle, S.E., \& Cheng, G. (2007) Cutting edge: involvement of the type I IFN production and signaling pathway in lipopolysaccharide-induced IL-10 production. J. Immunol., 178, 11, (June 2007), 6705-6709.

Chen, X., Yoza, B.K., El Gazzar, M., Hu, J.Y., Cousart, S.L., \& McCall, C.E. (2009) RelB sustains IkappaBalpha expression during endotoxin tolerance. Clin. Vaccine Immunol., 16, 1, (January 2009), 104-110.

Costinean, S., Zanesi, N., Pekarsky, Y., Tili, E., Volinia, S., Heerema, N., \& Croce, C.M. (2006) Pre-B cell proliferation and lymphoblastic leukemia/high-grade lymphoma in E(mu)-miR155 transgenic mice. Proc Natl Acad Sci U S A, 103, 18, (May 2006), 7024-7029.

Covert, M.W., Leung, T.H., Gaston, J.E., \& Baltimore, D. (2005) Achieving stability of lipopolysaccharideinduced NF-kappaB activation. Science, 309, 5742, (September 2005), 1854-1857.

De Santa, F., Totaro, M.G., Prosperini, E., Notarbartolo, S., Testa, G., \& Natoli G. (2007) The histone H3 lysine-27 demethylase Jmjd3 links inflammation to inhibition of polycomb-mediated gene silencing. Cell, 130, 6, (September 2007), 1083-1094. 
del Fresno, C., García-Rio, F., Gómez-Piña, V., Soares-Schanoski, A., Fernández-Ruíz, I., Jurado, T., Kajiji, T., Shu, C., Marín, E., Gutierrez del Arroyo, A., Prados, C., Arnalich, F., Fuentes-Prior, P., Biswas, S.K., \& López-Collazo, E. (2009) Potent phagocytic activity with impaired antigen presentation identifying lipopolysaccharide-tolerant human monocytes: demonstration in isolated monocytes from cystic fibrosis patients. J Immunol., 182, 10, (May 2009), 6494-6507.

del Fresno, C., Gómez-Piña, V., Lores, V., Soares-Schanoski, A., Fernández-Ruiz, I., Rojo, B., Alvarez-Sala, R., Caballero-Garrido, E., García, F., Veliz, T., Arnalich, F., Fuentes-Prior, P., García-Río, F., \& López-Collazo, E. (2008) Monocytes from cystic fibrosis patients are locked in an LPS tolerance state: down-regulation of TREM-1 as putative underlying mechanism. PLoS ONE, 3, 7, (July 2008), e2667.

del Fresno, C., Otero, K., Gómez-García, L., González-León, M.C., Soler-Ranger, L., FuentesPrior, P., Escoll, P., Baos, R., Caveda, L., García, F., Arnalich, F., \& López-Collazo, E. (2005) Tumor cells deactivate human monocytes by up-regulating IL-1 receptor associated kinase-M expression via CD44 and TLR4. J. Immunol., 174, 5, (March 2005), 3032-3040.

Delano, M.J., Scumpia, P.O., Weinstein, J.S., Coco, D., Nagaraj, S., Kelly-Scumpia, K.M., O'Malley, K.A., Wynn, J.L., Antonenko, S., Al-Quran, S.Z., Swan, R., Chung, C.S., Atkinson, M.A., Ramphal, R., Gabrilovich, D.I., Reeves, W.H., Ayala, A., Phillips, J., Laface, D., Heyworth, P.G., Clare-Salzler, M., \& Moldawer LL. (2007) MyD88-dependent expansion of an immature GR-1(+)CD11b(+) population induces T cell suppression and Th2 polarization in sepsis. J. Exp. Med., 204, 6, (June 2007), 1463-1474.

Dobrovolskaia, M.A. \& Vogel, S.N. (2002) Toll receptors, CD14, and macrophage activation and deactivation by LPS. Microbes Infect., 4, 9, (July 2002), 903-914.

Dobrovolskaia, M.A., Medvedev, A.E., Thomas, K.E., Cuesta, N., Toshchakov, V., Ren, T., Cody, M.J., Michalek, S.M., Rice, N.R., \& Vogel, S.N. (2003) Induction of in vitro reprogramming by Toll-like receptor (TLR)2 and TLR4 agonists in murine macrophages: effects of TLR "homotolerance" versus "heterotolerance" on NFkappa B signaling pathway components. J Immunol., 170, 1, (January 2003), 508-519.

Draisma, A., Pickkers, P., Bouw, M.P., \& van der Hoeven, J.G. (2009) Development of endotoxin tolerance in humans in vivo. Crit Care Med., 37, 4, (April 2009), 12611267.

Efron, P.A., Martins, A., Minnich, D., Tinsley, K., Ungaro, R., Bahjat, F.R., Hotchkiss, R., Clare-Salzler, M., \& Moldawer, L.L. (2004) Characterization of the systemic loss of dendritic cells in murine lymph nodes during polymicrobial sepsis. J. Immunol., 173, 5, (September 2004), 3035-3043.

El Gazzar, M., Yoza, B.K., Chen, X., Garcia, B.A., Young, N.L., \& McCall, C.E. (2009) Chromatin-specific remodeling by HMGB1 and linker histone H1 silences proinflammatory genes during endotoxin tolerance. Mol. Cell Biol., 29, 7, (April 2009), 1959-1971.

El Gazzar, M. \& McCall, C.E. (2010) MicroRNAs distinguish translational from transcriptional silencing during endotoxin tolerance. J Biol Chem., 285, 27, (July 2010), 20940-20951.

El Gazzar, M., Church, A., Liu, T., \& McCall, C.E. (2011) MicroRNA-146a regulates both transcription silencing and translation disruption of TNF-\{alpha\} during TLR4induced gene reprogramming. J Leukoc Biol., 90, 3, September 2011), 509-519. 
Escoll, P., del Fresno, C., García, L., Vallés, G., Lendínez, M.J., Arnalich, F., \& López-Collazo, E. (2003) Rapid up-regulation of IRAK-M expression following a second endotoxin challenge in human monocytes and in monocytes isolated from septic patients. Biochem Biophys Res Commun., 311, 2, (November 2003), 465-472.

Fadok, V.A., Bratton, D.L., Konowal, A., Freed, P.W., Westcott, J.Y., \& Henson, P.M. (1998) Macrophages that have ingested apoptotic cells in vitro inhibit proinflammatory cytokine production through autocrine/paracrine mechanisms involving TGF-beta, PGE2, and PAF. J. Clin. Invest., 101, 4, (February 1998), 890-898.

Fan, H. \& Cook, J.A. (2004) Molecular mechanisms of endotoxin tolerance. J Endotoxin Res., $10,2,71-84$.

Foster, S.L. \& Medzhitov, R. (2009) Gene-specific control of the TLR-induced inflammatory response. Clin Immunol., 130, 1, (January 2009), 7-15.

Foster, S.L., Hargreaves, D.C., \& Medzhitov, R. (2007) Gene-specific control of inflammation by TLR-induced chromatin modifications. Nature, 447, 7147, (June 2007), 972-978.

Gautier, E.L., Huby, T., Saint-Charles, F., Ouzilleau, B., Chapman, M.J., \& Lesnik, P. (2008) Enhanced dendritic cell survival attenuates lipopolysaccharide-induced immunosuppression and increases resistance to lethal endotoxic shock. J. Immunol., 180, 10, (May 2008), 6941-6946.

Gibot, S., Kolopp-Sarda, M.N., Béné, M.C., Bollaert, P.E., Lozniewski, A., Mory, F., Levy, B., \& Faure, G.C. (2004) A soluble form of the triggering receptor expressed on myeloid cells-1 modulates the inflammatory response in murine sepsis. J Exp Med., 200, 11, (December 2004), 1419-1426.

Gilchrist, M., Thorsson ,V., Li ,B., Rust, A.G., Korb, M., Roach, J.C., Kennedy, K., Hai, T., Bolouri, H., \& Aderem, A. (2006) Systems biology approaches identify ATF3 as a negative regulator of Toll-like receptor 4. Nature, 441, 7090, (May 2006), 173-178.

Gordon, S. \& Taylor, P.R. (2005) Monocyte and macrophage heterogeneity. Nat Rev Immunol., 5, 12, (December 2005), 953-964.

Hacker, H., Redecke, V., Blagoev, B., Kratchmarova, I., Hsu, L.C., Wang, G.G., Kamps, M.P., Raz, E., Wagner, H., Häcker, G., Mann, M., \& Karin, M. (2006) Specificity in Toll-like receptor signaling through distinct effector functions of TRAF3 and TRAF6. Nature, 439, 7073, (January 2006), 204-207.

Hayden, M.S. \& Ghosh, S. (2008) Shared principles in NF-kappaB signaling. Cell, 132, 3, (February 2008), 344-362.

Hotchkiss, R.S. \& Karl, I.E. (2003) The pathophysiology and treatment of sepsis. N. Engl. J. Med., 348, 2, (January 2003), 138-150.

Hotchkiss, R.S., Tinsley, K.W., Swanson, P.E., Grayson, M.H., Osborne, D.F., Wagner, T.H., Cobb, J.P., Coopersmith, C., \& Karl, I.E. (2002) Depletion of dendritic cells, but not macrophages, in patients with sepsis. J. Immunol., 168, 5, (March 2002), 24932500 .

Hotchkiss, R.S., Coopersmith, C.M., McDunn, J.E., \& Ferguson T.A. (2009) The sepsis seesaw: tilting toward immunosuppression. Nat Med., 15, 5, (May 2009), 496-497.

Iwasaki, A. \& Medzhitov, R. (2010) Regulation of adaptive immunity by the innate immune system. Science, 327, 5963, (January 2010), 291-295.

Kawai, T. \& Akira, S. (2011) Toll-like receptors and their crosstalk with other innate receptors in infection and immunity. Immunity, 34, 5, (May 2011), 637-650. 
Kayama, H., Ramirez-Carrozzi, V.R., Yamamoto, M., Mizutani, T., Kuwata, H., Iba, H., Matsumoto, M., Honda, K., Smale, S.T., \& Takeda, K. (2008) Class-specific regulation of pro-inflammatory genes by MyD88 pathways and IkappaBzeta. J. Biol. Chem., 283, 18, (May 2008), 12468-12477.

Kim, Y.G., Park, J.H., Daignault, S., Fukase, K., \& Núñez, G. (2008) Cross-tolerization between Nod1 and Nod2 signaling results in reduced refractoriness to bacterial infection in Nod2-deficient macrophages. J Immunol., 181, 6, (September 2008), 4340-4346.

Kobayashi, K., Hernandez, L.D., Galán, J.E., Janeway, C.A. Jr., Medzhitov, R., \& Flavell, R.A. (2002) IRAK-M is a negative regulator of Toll-like receptor signaling. Cell, 110, 2, (July 2002), 191-202.

Kuang, D.M., Wu, Y., Chen, N., Cheng, J., Zhuang, S.M., \& Zheng, L. (2007) Tumor-derived hyaluronan induces formation of immunosuppressive macrophages through transient early activation of monocytes. Blood, 110, 2, (July 2007), 587-595.

Kwon, A.H., Qiu, Z., Nagahama, H., Kaibori, M., \& Kamiyama, Y. (2004) Fibronectin suppresses apoptosis and protects mice from endotoxic shock. Transplantation proceedings, 36, 8, (October 2004), 2432-2435.

Lauw, F.N., ten Hove, T., Dekkers, P.E., de Jonge, E., van Deventer, S.J., \& van Der Poll, T. (2000) Reduced Th1, but not Th2, cytokine production by lymphocytes after in vivo exposure of healthy subjects to endotoxin. Infect. Immun., 68, 3, (March 2000), 10141018.

Lawrence, T. Gilroy, D.W., Colville-Nash, P.R., \& Willoughby, D.A. (2001) Possible new role for NF-kappaB in the resolution of inflammation. Nat. Med., 7, 12, (December 2001), 1291-1297.

Liew, F.Y., Xu, D., Brint, E.K., \& O'Neill, L.A. (2005) Negative regulation of toll-like receptormediated immune responses. Nat. Rev. Immunol., 5, 6, (June 2005), 446-458.

Liu, Y.Y., Lee, C.H., Dedaj, R., Zhao, H., Mrabat, H., Sheidlin, A., Syrkina, O., Huang, P.M., Garg, H.G., Hales, C.A., \& Quinn, D.A. (2008) High-molecular-weight hyaluronan-a possible new treatment for sepsis-induced lung injury: a preclinical study in mechanically ventilated rats. Crit. Care (London, England), 12, 4, R102.

Liu, Y., Chen, Q., Song, Y., Lai, L., Wang, J., Yu, H., Cao, X., \& Wang, Q. (2011) MicroRNA98 negatively regulates IL-10 production and endotoxin tolerance in macrophages after LPS stimulation. FEBS Lett., 585, 12, (June 2011), 1963-1968.

Lopez-Collazo, E., Fuentes-Prior, P., Arnalich, F., \& del Fresno, C. (2006) Pathophysiology of interleukin-1 receptor-associated kinase-M: implications in refractory state. Curr. Opin. Infect. Dis., 19, 3, (June 2006), 237-244.

Mages, J., Dietrich, H., \& Lang, R. (2007) A genome-wide analysis of LPS tolerance in macrophages. Immunobiology, 212, 9-10, 723-737.

Manjuck, J., Saha, D.C., Astiz, M., Eales, L.J., \& Rackow, E.C. (2000) Decreased response to recall antigens is associated with depressed costimulatory receptor expression in septic critically ill patients. J. Lab. Clin. Med., 135, 2, (February 2000), 153-160.

Mantovani, A. (2008) From phagocyte diversity and activation to probiotics: back to Metchnikoff. Eur. J. Immunol., 38, 12, (December 2008), 3269-3273.

Mantovani, A., Sica, A., \& Locati, M. (2005) Macrophage polarization comes of age. Immunity, 23, 4, (October 2005), 344-346. 
Mantovani, A., Sica, A., Sozzani, S., Allavena, P., Vecchi, A., \& Locati, M. (2004) The chemokine system in diverse forms of macrophage activation and polarization. Trends Immunol., 25, 12, (December 2004), 677 - 686.

Mantovani, A. \& Sica, A. (2010) Macrophages, innate immunity and cancer: balance, tolerance, and diversity. Curr Opin Immunol., 22, 2, (April 2010), 231-237.

Medvedev, A.E., Kopydlowski, K.M., \& Vogel, S.N. (2000) Inhibition of lipopolysaccharideinduced signal transduction in endotoxin-tolerized mouse macrophages: dysregulation of cytokine, chemokine, and toll-like receptor 2 and 4 gene expression. J Immunol., 164, 11, (June 2000), 5564-5574.

Melo, E.S., Barbeiro, D.F., Gorjão, R., Rios, E.C., Vasconcelos, D., Velasco, I.T., Szabo, C., Curi, R., de Lima-Salgado, T.M., \& Soriano, F.G. (2010) Gene expression reprogramming protects macrophage from septic-induced cell death. Mol Immunol., 47, 16, (October 2010), 2587-2593.

Monneret, G., Finck, M.E., Venet, F., Debard, A.L., Bohé, J., Bienvenu, J., \& Lepape, A. (2004) The anti-inflammatory response dominates after septic shock: association of low monocyte HLA-DR expression and high interleukin-10 concentration. Immunol Lett., 95, 2, (September 2004), 193-198.

Monneret, G., Venet, F., Pachot, A., \& Lepape A. (2008) Monitoring immune dysfunctions in the septic patient: a new skin for the old ceremony. Molecular medicine (Cambridge, Mass), 14, 1-2, (January-February 2008), 64-78.

Mosser, D.M. \& Edwards, J.P. (2008) Exploring the full spectrum of macrophage activation. Nat Rev Immunol., 8, 12, (December 2008), 958-969.

Munoz, C., Carlet, J., Fitting, C., Misset, B., Blériot, J.P., \& Cavaillon, J.M. (1991a) Dysregulation of in vitro cytokine production by monocytes during sepsis. J. Clin. Invest., 88, 5, (November 1991), 1747-1754.

Munoz, C., Misset, B., Fitting, C., Blériot, J.P., Carlet, J., \& Cavaillon, J.M. (1991b) Dissociation between plasma and monocyte-associated cytokines during sepsis. Eur. J. Immunol., 21, 9, (September 1991), 2177-2184.

Nahid, M.A, Satoh, M., \& Chan E.K.L. (2011) MicroRNA in TLR signalling and endotoxin tolerance. Cellular \& Molecular Immunology, In press (doi: 10.1038/cmi.2011.26).

Nathan, C. (2002) Points of control in inflammation. Nature, 420, 6917, (December 2002), 846852.

Netea, M.G., Quintin, J., \& van der Meer, J.W. (2011) Trained immunity: a memory for innate host defense. Cell Host Microbe., 9, 5, (May 2011), 355-361.

Nimah, M., Zhao, B., Denenberg, A.G., Bueno, O., Molkentin, J., Wong, H.R., \& Shanley, T.P. (2005) Contribution of MKP-1 regulation of p38 to endotoxin tolerance. Shock, 23, 1, (January 2005), 80-87.

O'Connell, R.M. Taganov, K.D., Boldin, M.P., Cheng, G., \& Baltimore, D. (2007) MicroRNA155 is induced during the macrophage inflammatory response. Proc Natl Acad Sci $U$ $S$ A, 104, 5, (January 2007), 1604-1609.

Ogawa, H., Rafiee, P., Heidemann, J., Fisher, P.J., Johnson, N.A., Otterson, M.F., Kalyanaraman, B., Pritchard, K.A.Jr., \& Binion, D.G. (2003) Mechanisms of endotoxin tolerance in human intestinal microvascular endothelial cells. $J$. Immunol., 170, 12, (June 2003), 5956-5964.

O'Neill, L.A. \& Bowie, A.G. (2007) The family of five: TIR-domain-containing adaptors in Toll-like receptor signalling. Nat Rev Immunol., 7, 5, (May 2007), 353-364. 
Pachot, A., Lepape, A., Vey, S., Bienvenu, J., Mougin, B., \& Monneret, G. (2006) Systemic transcriptional analysis in survivor and non-survivor septic shock patients: a preliminary study. Immunol. Lett., 106, 1, (July 2006), 63-71.

Palsson-McDermott, E.M., Doyle, S.L., McGettrick, A.F., Hardy, M., Husebye, H., Banahan, K., Gong, M., Golenbock, D., Espevik, T., \& O'Neill, L.A. (2009) TAG, a splice variant of the adaptor TRAM, negatively regulates the adaptor MyD88independent TLR4 pathway. Nat. Immunol., 10, 6, (June 2009), 579-586.

Parker, L.C., Jones, E.C., Prince, L.R., Dower, S.K., Whyte, M.K., \& Sabroe, I. (2005) Endotoxin tolerance induces selective alterations in neutrophil function. J. Leukoc. Biol., 78, 6, (December 2005), 1301-1305.

Pena, O.M., Pistolic, J., Raj, D., Fjell, C.D., \& Hancock, R.E. (2011) Endotoxin tolerance represents a distinctive state of alternative polarization(M2) in human mononuclear cells. J Immunol., 186, 12, (June 2011), 7243-7254.

Porta, C., Rimoldi, M., Raes, G., Brys, L., Ghezzi, P., Di Liberto, D., Dieli, F., Ghisletti, S., Natoli, G., De Baetselier, P., Mantovani, A., \& Sica, A. (2009) Tolerance and M2 (alternative) macrophage polarization are related processes orchestrated by p50 nuclear factor kappaB. Proc Natl Acad Sci U S A, 106, 35, (September 2009), 1497814983.

Ramirez-Carrozzi, V.R., Nazarian, A.A., Li, C.C., Gore, S.L., Sridharan, R. Imbalzano, A.N., \& Smale, S.T. (2006) Selective and antagonistic functions of SWI/SNF and Mi2beta nucleosome remodeling complexes during an inflammatory response. Genes Dev., 20, 3, (February 2006), 282-296.

Rauh, M.J., Ho, V., Pereira, C., Sham, A., Sly, L.M., Lam, V., Huxham, L., Minchinton, A.I., Mui, A., \& Krystal, G. (2005) SHIP represses the generation of alternatively activated macrophages. Immunity, 23, 4, (October 2005), 361-374.

Rothlin, C.V., Ghosh, S., Zuniga, E.I., Oldstone, M.B., \& Lemke, G. (2007) TAM receptors are pleiotropic inhibitors of the innate immune response. Cell, 131, 6, (December 2007), 1124-1136.

Sato, S., Nomura, F., Kawai, T., Takeuchi, O., Mühlradt, P.F., Takeda, K., \& Akira, S. (2000) Synergy and cross-tolerance between toll-like receptor (TLR) 2- and TLR4-mediated signaling pathways. J Immunol., 165, 12, (December 2000), 7096-7101.

Satoh, T., Takeuchi, O., Vandenbon, A., Yasuda, K., Tanaka, Y., Kumagai, Y., Miyake, T., Matsushita, K., Okazaki, T., Saitoh, T., Honma, K., Matsuyama, T., Yui, K., Tsujimura, T., Standley, D.M., Nakanishi, K., Nakai, K., \& Akira, S. (2010) The Jmjd3-Irf4 axis regulates M2 macrophage polarization and host responses against helminth infection. Nat Immunol., 11, 10, (October 2010), 936-944.

Schroder, M., Meisel, C., Buhl, K., Profanter, N., Sievert, N., Volk, H.D., \& Grütz, G. (2003) Different modes of IL-10 and TGF-beta to inhibit cytokine-dependent IFN-gamma production: consequences for reversal of lipopolysaccharide desensitization. J Immunol., 170, 10, (May 2003), 5260-5267.

Serhan, C.N., Brain, S.D., Buckley, C.D., Gilroy, D.W., Haslett, C., O'Neill, L.A., Perretti, M., Rossi, A.G., \& Wallace, J.L. (2007) Resolution of inflammation: state of the art, definitions and terms. FASEB J., 21, 2, (February 2007), 325-332.

Sharabi, A.B., Aldrich, M., Sosic, D., Olson, E.N., Friedman, A.D., Lee, S.H., \& Chen, S.Y. (2008) Twist-2 controls myeloid lineage development and function. PLoS Biol., 6, 12, (December 2008), e316. 
Sheedy, F.J., Palsson-McDermott, E., Hennessy, E.J., Martin, C., O'Leary, J.J., Ruan, Q., Johnson, D.S., Chen, Y., \& O'Neill, L.A. (2010) Negative regulation of TLR4 via targeting of the proinflammatory tumor suppressor PDCD4 by the microRNA miR21. Nat Immunol., 11, 2, (February 2010), 141-147.

Souza, D.G., Vieira, A.T., Soares, A.C., Pinho, V., Nicoli, J.R., Vieira, L.Q., \& Teixeira, M.M. (2004) The essential role of the intestinal microbiota in facilitating acute inflammatory responses. J Immunol., 173, 6, (September 2004), 4137-4146.

Taganov, K.D. Boldin, M.P., Chang, K.J., \& Baltimore, D. (2006) NF-kappaB-dependent induction of microRNA miR-146, an inhibitor targeted to signaling proteins of innate immune responses. Proc Natl Acad Sci U S A, 103, 33, (August 2006), 1248112486.

Tili, E., Michaille, J.J., Cimino, A., Costinean, S., Dumitru, C.D., Adair, B., Fabbri, M., Alder, H., Liu, C.G., Calin, G.A., \& Croce, C.M. (2007) Modulation of miR-155 and miR$125 \mathrm{~b}$ levels following lipopolysaccharide/TNF-alpha stimulation and their possible roles in regulating the response to endotoxin shock. J. Immunol., 179, 8, (October 2007), 5082-5089.

van 't Veer, C., van den Pangaart, P.S., van Zoelen, M.A., de Kruif, M., Birjmohun, R.S., Stroes, E.S., de Vos, A.F., \& van der Poll, T. (2007) Induction of IRAK-M is associated with lipopolysaccharide tolerance in a human endotoxemia model. J Immunol., 179, 10, (November 2007), 7110-7120.

Willment, J.A., Lin, H.H., Reid, D.M., Taylor, P.R., Williams, D.L., Wong, S.Y., Gordon, S., \& Brown, G.D. (2003) Dectin-1 expression and function are enhanced on alternatively activated and GM-CSF-treated macrophages and are negatively regulated by IL-10, dexamethasone, and lipopolysaccharide. J. Immunol., 171, 9, (November 2003), 4569-4573.

Wilson, A.G. (2008) Epigenetic regulation of gene expression in the inflammatory response and relevance to common diseases. J. Periodontol., 79, 8 Suppl, (August 2008), 15141519.

Wolk, K., Döcke, W.D., von Baehr, V., Volk, H.D., \& Sabat, R. (2000) Impaired antigen presentation by human monocytes during endotoxin tolerance. Blood, 96, 1, (July 2000), 218-223.

Wolk, K., Kunz, S., Crompton, N.E., Volk, H.D., \& Sabat, R. (2003) Multiple mechanisms of reduced major histocompatibility complex class II expression in endotoxin tolerance. J Biol Chem., 278, 20, May 2003, 18030-18036.

Wysocka, M., Robertson, S., Riemann, H., Caamano, J., Hunter, C., Mackiewicz, A., Montaner, L.J., Trinchieri, G., \& Karp, C.L. (2001) IL-12 suppression during experimental endotoxin tolerance: dendritic cell loss and macrophage hyporesponsiveness. J. Immunol., 166, 12, (June 2001), 7504-7513.

Yamamoto, M., Sato, S., Hemmi, H., Hoshino, K., Kaisho, T., Sanjo, H., Takeuchi, O., Sugiyama, M., Okabe, M., Takeda, K., Akira, S. (2003) Role of adaptor TRIF in the MyD88-independent toll-like receptor signaling pathway. Science, 301, 5633, (August 2003), 640-643.

Ziegler-Heitbrock, L. (2001) The p50-homodimer mechanism in tolerance to LPS. J. Endotoxin Res., 7, 3, 219-222. 


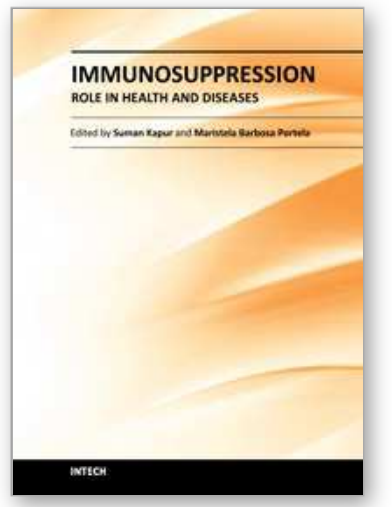

\author{
Immunosuppression - Role in Health and Diseases \\ Edited by Dr. Suman Kapur
}

ISBN 978-953-51-0152-9

Hard cover, 470 pages

Publisher InTech

Published online 24, February, 2012

Published in print edition February, 2012

A need for a book on immunology which primarily focuses on the needs of medical and clinical research students was recognized. This book, "Immunosuppression - Role in Health and Diseases" is relatively short and contains topics relevant to the understanding of human immune system and its role in health and diseases. Immunosuppression involves an act that reduces the activation or efficacy of the immune system. Therapeutic immunosuppression has applications in clinical medicine, ranging from prevention and treatment of organ/bone marrow transplant rejection, management of autoimmune and inflammatory disorders. It brings important developments both in the field of molecular mechanisms involved and active therapeutic approaches employed for immunosuppression in various human disease conditions. There was a need to bring this information together in a single volume, as much of the recent developments are dispersed throughout biomedical literature, largely in specialized journals. This book will serve well the practicing physicians, surgeons and biomedical scientists as it provides an insight into various approaches to immunosuppression and reviews current developments in each area.

\title{
How to reference
}

In order to correctly reference this scholarly work, feel free to copy and paste the following:

Subhra K. Biswas and Irina N. Shalova (2012). Endotoxin Tolerance as a Key Mechanism for Immunosuppression, Immunosuppression - Role in Health and Diseases, Dr. Suman Kapur (Ed.), ISBN: 978953-51-0152-9, InTech, Available from: http://www.intechopen.com/books/immunosuppression-role-in-healthand-diseases/endotoxin-tolerance-as-a-key-mechanism-for-immunosuppression

\section{INTECH}

open science | open minds

\section{InTech Europe}

University Campus STeP Ri

Slavka Krautzeka 83/A

51000 Rijeka, Croatia

Phone: +385 (51) 770447

Fax: +385 (51) 686166

www.intechopen.com

\section{InTech China}

Unit 405, Office Block, Hotel Equatorial Shanghai

No.65, Yan An Road (West), Shanghai, 200040, China 中国上海市延安西路65号上海国际贵都大饭店办公楼405单元

Phone: +86-21-62489820

Fax: +86-21-62489821 
(C) 2012 The Author(s). Licensee IntechOpen. This is an open access article distributed under the terms of the Creative Commons Attribution 3.0 License, which permits unrestricted use, distribution, and reproduction in any medium, provided the original work is properly cited. 